\title{
Do the classification of areas and distance matter to the assessment results of achieving the treatment targets among type 2 diabetes patients?
}

Maija Toivakka ${ }^{1 *}$, Tiina Laatikainen ${ }^{2,3,4}$, Timo Kumpula and Markku Tykkyläinen ${ }^{1}$

\begin{abstract}
Background: Type 2 diabetes is a major health concern all over the world. The prevention of diabetes is important but so is well-balanced diabetes care. Diabetes care can be influenced by individual and neighborhood socio-economic factors and geographical accessibility to health care services. The aim of the study is to find out whether two different area classifications of urban and rural areas give different area-level results of achieving the targets of control and treatment among type 2 diabetes patients exemplified by a Finnish region. The study exploits geo-referenced patient data from a regional primary health care patient database combined with postal code area-level socio-economic variables, digital road data and two grid based classifications of areas: an urban-rural dichotomy and a classification with seven area types.
\end{abstract}

Methods: The achievement of control and treatment targets were assessed using the patient's individual laboratory data among 9606 type 2 diabetes patients. It was assessed whether hemoglobin A1c (HbA1c) was controlled and whether the recommended level of $\mathrm{HbA} 1 \mathrm{c}$ was achieved in patients by different area classes and as a function of distance. Chi square test and logistic regression analysis were used for testing.

Results: The study reveals that area-level inequalities exist in the care of type 2 diabetes in a detailed 7-class area classification but if the simple dichotomy of urban and rural is applied differences vanish. The patient's gender and age, area-level education and the area class they belonged to were associated with achievements of control and treatment targets. Longer distance to health care services was not a barrier to good achievements of control or treatment targets.

Conclusions: A more detailed grid-based area classification is better for showing spatial differences in the care of type 2 diabetes patients. Inequalities exist but it would be misleading to state that the differences are simply due to urban or rural location or due to distance. From a planning point of view findings suggest that detailed geo-coded patient information could be utilized more in resourcing and targeting the health care services to find the area-level needs of care and to improve the cost-efficient allocation of resources.

Keywords: Area classifications, Accessibility, Rural health, Urban health, Care outcomes, Type 2 diabetes

\footnotetext{
*Correspondence: maija.toivakka@uef.fi

${ }^{1}$ Department of Geographical and Historical Studies, University of Eastern

Finland, P.O. Box 111, 80101 Joensuu, Finland

Full list of author information is available at the end of the article
} 


\section{Background Introduction}

Type 2 diabetes continues to be a major health burden globally [1]. The changes in lifestyle and in particular the increasing rates of obesity are affecting the increase of diabetes prevalence across the world [1-3]. The prevention of diabetes is important but so is well-balanced diabetes care. Good management of type 2 diabetes improves the quality of life of the patients, reduces complications among patients [4], decreases the risk of comorbidities [5] and reduces the economic burden [6, 7].

Socio-economic inequalities in diabetes care do exist [8]. Achievement of the treatments targets in the diabetes care are affected by individual $[9,10]$ and neighborhood [11-13] socio-economic status (SES). It is commonly believed that poor geographical accessibility to health care services may lead to delayed care and underuse of health care and this is believed to be the case especially among residents living in rural areas [14]. However, it should be kept in mind that rural health and health in general are interrelated with broader social, economic, political, cultural, historical $[15,16]$ and spatial structures.

In Finland, primary care is available to all residents and is delivered mainly in public health care centers by general practitioners (GPs). Most of the population lives reasonably close to the nearest health service provider, but in rural areas there are some long distances. In some areas, the availability of public transport is inadequate. However, some of the chronic disease patients are entitled to reimbursements for transportation to be able to attend the regular check-ups.

The aim of the study is to find out whether two different area classifications give significantly different area-level results of achieving the targets of control and treatment among type 2 diabetes patients exemplified by a Finnish region of North Karelia, equivalent in area to New Jersey or 7/10 of Belgium. The focus is to reveal and compare the possible spatial health care divergences by using 2-class (less detailed) and 7-class (detailed) grid based classifications of urban and rural areas. The first hypothesis is that the 7-class classification is better for showing differences in urban and rural areas in the care of type 2 diabetes patients. The second hypothesis claims that the longer the distance to the health center is the more it deteriorates the achievement of control and treatment targets. The study exploits individual geo-referenced type 2 diabetes patient record data from a regional primary health care patient database combined with postal code area-level socio-economic variables, digital road data and grid based classifications of areas.

\section{Classifications of urban and rural areas}

The absence of a generally accepted definition of urban and rural area types makes it difficult to examine spatial health and health care inequalities in a valid way and in particular to compare the results between different countries $[17,18]$. This might be one reason for varying results on health and health care inequalities in and between urban and rural areas. It has been suggested that these inequalities should be examined across different settlement types and should not just rely on an urban-rural dichotomy $[16,19,20]$.

Often the definitions of urban and rural are based on population density and distance to certain functions such as services [21, 22]. Definitions are usually developed for a certain purpose and generalization can lead to lack of explanatory variation [22]. Traditionally, countries provide the classifications of urban and rural areas based on different indicators, and usually these areas are consistent with the administrative borders such as counties, municipalities, census blocks or census tracts.

However, grid based classifications also exist. In England and Wales urban and rural areas (RUC: RuralUrban Definition for Small Area Geographies) have been classified for policy purposes by using 1 hectare grid cells [23]. The Organization for Economic Cooperation and Development (OECD) and the European Commission have developed a grid based harmonized definition of cities in Europe which improves cross-country analysis of cities [24]. Grid based and comparable on-task tailored classifications absorb more variation than conventional classifications and thus could be more useful in health related studies.

Helminen et al. [25] have developed a grid based 7-class classification of urban and rural areas for Finland in 2014. Before that, the multiclass classifications of urban and rural areas for various policy purposes were based on municipal borders. Old classification methods became problematic and outdated as many municipalities merged in 2009-2012 creating commuter belts where both urban and rural characteristics could be identified. The new classification procedure is well documented and could be produced for other countries as well.

The 2014 Finnish area classification divides urban areas into three (inner, outer, peri-urban) classes and rural areas into four (local centers in rural areas, rural areas close to urban areas, rural heartland areas and sparsely populated rural areas) classes [26]. It depicts settlement structures focusing on population density, relative location, land use and economic structures. This classification system uses geospatial data represented by a $250 \times 250 \mathrm{~m}$ grid of cells. Data on population, labor, commuting, buildings, roads and land use have been used. Based on the data, variables describing the amount, 
density, efficiency, accessibility, intensity, versatility and orientation of the areas have been calculated. Each cell is classified into one of the seven classes according to the defined criteria. All seven area classes are found in the study region described later (Fig. 1).

The Finnish Environment Institute maintains a classification on population centers (known also as statistical locality), which is provided by Statistics Finland. All clusters of buildings with at least 200 inhabitants are defined as population centers [27]. The definition utilizes the building and population data of Statistics Finland's $250 \times 250 \mathrm{~m}$ grid data. The definition takes into account the population size, number of buildings and their floor area. The distance between buildings included in population centers is $200 \mathrm{~m}$ at maximum with certain exceptions. This categorization was also used in this study to include a simple urban-rural dichotomy (Fig. 1). The patients living in population centers reside in urban areas and the patients living outside the population centers reside in rural areas. The study region of North Karelia is more rural as $70.3 \%$ of the population lived in population centers compared with the Finnish total urban population of $83.7 \%$ in 2012 [28].

\section{Accessibility of health care services}

The accessibility of health care services is affected by the locations of both the health care provider and the patient. According to Penchansky and Thomas [29] accessibility (distance, transportation, travel time and cost) is one of the five dimensions of access among availability (the supply of services), accommodation (hours of operation, waiting times), affordability (price of services) and acceptability (clients' satisfaction). The poorer the accessibility is the larger the disadvantage is made up by the friction of distance. Further on, accessibility can mean either the potential or revealed accessibility [30-32]. Potential accessibility consists of estimated values often based on surrogate variables, whereas revealed accessibility means the actual use of health care services, thus the health care service utilization [30]. Much of the research is focused on the methodology of measuring potential accessibility [31, 33-37] but less on revealed accessibility and its effects on the outcomes of care.

Transportation options, transportation costs and distance to a health care provider differ depending on the domicile of each patient. Poorer accessibility to health care services is believed to lead to poorer health outcomes [14]. Commonly it is thought that utilization decreases as distance increases. However, the effects of distance vary depending on the health service under consideration [30, 32].

Although distance may influence health care utilization, it is not a barrier to chronic care [38], and patients will travel longer distances for check-ups or for chronic conditions [39]. Mixed evidence is found in the care of diabetes. Driving distance has not been associated with care outcomes within urban settings in Canada [40], and differences in care outcomes have not been found between rural and urban patients in Australia and the USA [41, 42]. In some cases driving distance has been associated with care outcomes in rural areas in the USA $[43,44]$. These diabetes related studies used very different definitions of urban and rural or did not define them at all.

\section{Methods}

\section{Study region and data}

The region of North Karelia (13 municipalities, 165,800 inhabitants, population density of $9.3 / \mathrm{km}^{2}$ ) in Eastern Finland is characterized by a regional center $(75,000$ inhabitants) providing both primary and specialized health care services and there are 24 health care centers in the region. Every patient belongs to a service area of a certain health care center based on the postal code area in which they live.

At the end of the year 2012 approximately $6 \%$ ( $\mathrm{n}=10,204)$ of the population in North Karelia had a diagnosed type 2 diabetes. All patient documents have been filed to the regional patient database and individual level data (on e.g. the place of domicile, gender, age, laboratory analyses) was retrieved from this database for every patient who had type 2 diabetes diagnosis (ICD-10 code E11). The data acquisition from the care provider, approved by the ethics committee of the North Savo Hospital District, is described in detail elsewhere [13]. Individual level socio-economic information was minimal, whereupon the postal code area-level data of a patient's domicile were utilized for describing the socio-economic environment of each patient to see in what kinds of neighborhoods they live. The socio-economic characteristics (Table 1) of the postal code areas were retrieved from the Statistics Finland's database [45].

From the original patient group $94.1 \%(\mathrm{n}=9606)$ were geocoded by address-matching in ArcGIS 10.2.1 software by using Digiroad. The Finnish Transport Agency maintains the national road and street database, Digiroad, which contains precise and accurate data on the location of all roads and streets and address information in Finland. The road distance from a patient's home to the health care center was calculated using origin-destination cost matrix analysis provided by the software. The travel distance of each patient by road was used because patient record data does not provide information about how the patients usually travel (by car, walking, by public transport). Therefore neither travel time, the way of moving nor the real costs were available. 


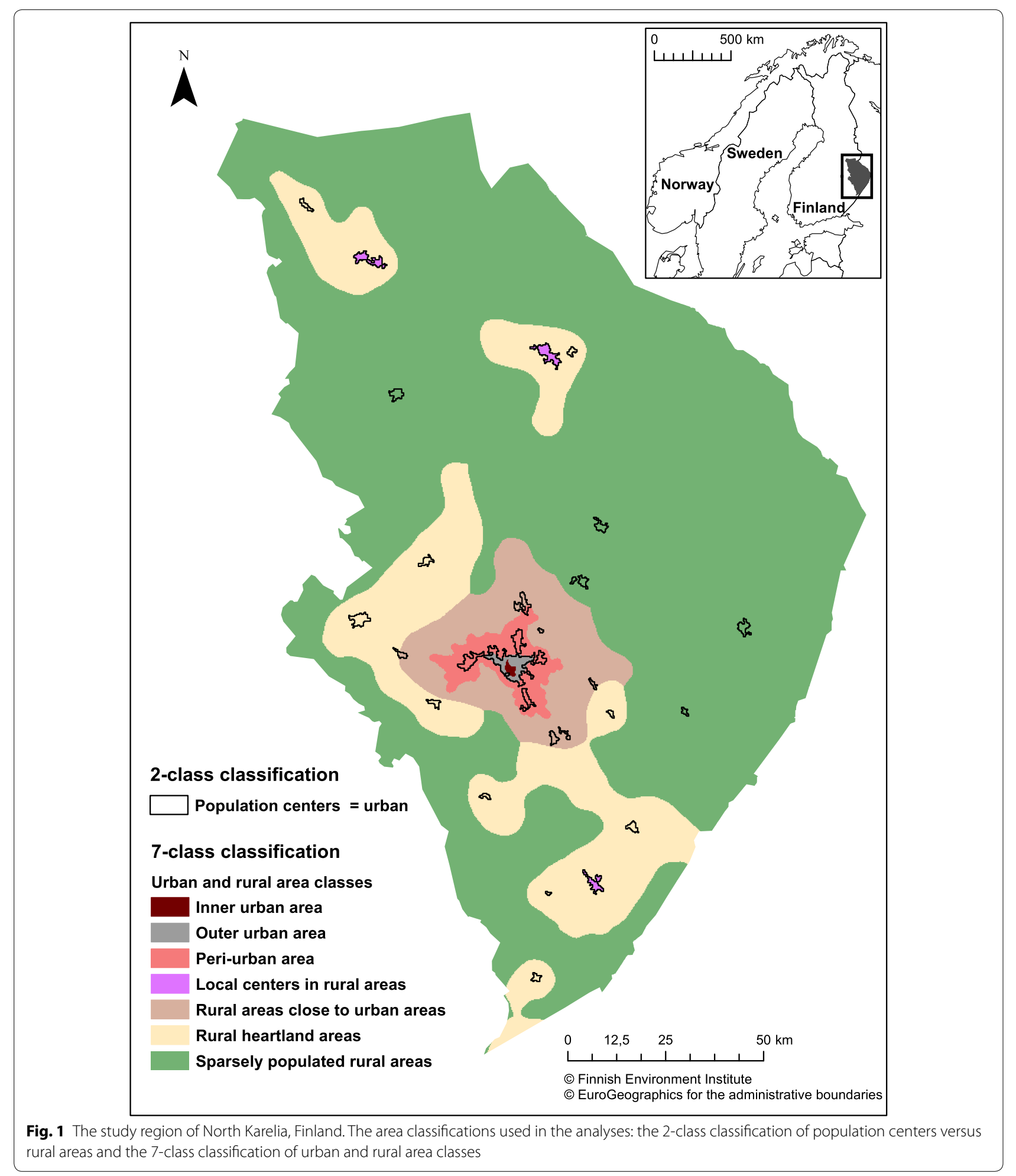

\section{Achievement of the control and treatment targets}

Finnish Current Care Guidelines form the basis of the treatment and management of diseases and risk factors in health care [46]. Guidelines for diabetes recommends that the hemoglobin A1c (HbA1c) level should be lower than $7.0 \%(53 \mathrm{mmol} / \mathrm{mol})$ and that it should be measured every 3-6 months in diabetes patients [47]. HbA1c provides long-term blood sugar levels and it is a good 
Table 1 Patients' mean age and area-level characteristics in different area classes

\begin{tabular}{|c|c|c|c|c|c|}
\hline Area classes & $\begin{array}{l}\text { Patients' } \\
\text { mean age }\end{array}$ & $\begin{array}{l}\text { Mean age } \\
\text { by area }\end{array}$ & $\begin{array}{l}\text { Educated (\%) } \\
\text { by area }^{a}\end{array}$ & $\begin{array}{l}\text { Unemployed (\%) } \\
\text { by area }\end{array}$ & $\begin{array}{l}\text { Median income } \\
\text { (thousands/€) by area }\end{array}$ \\
\hline Inner urban area & 71.7 & 43.6 & 76.6 & 5.9 & 16.854 \\
\hline Outer urban area & 65.7 & 39.1 & 76.3 & 8.2 & 18.398 \\
\hline Peri-urban area & 64.9 & 36.0 & 79.3 & 5.0 & 22.740 \\
\hline Local centers in rural areas & 69.9 & 48.2 & 60.6 & 7.5 & 15.817 \\
\hline Rural areas close to urban areas & 67.8 & 40.7 & 70.8 & 6.3 & 18.299 \\
\hline Rural heartland areas & 68.2 & 47.0 & 60.5 & 6.9 & 15.265 \\
\hline Sparsely populated rural areas & 67.4 & 48.4 & 56.4 & 7.2 & 14.936 \\
\hline Population center = urban & 68.7 & 44.3 & 67.1 & 7.0 & 16.941 \\
\hline Outside population center $=$ rural & 66.1 & 45.9 & 61.6 & 7.0 & 15.861 \\
\hline
\end{tabular}

a At least high school graduate or vocational training

indicator for the good quality of care. It is widely used to measure the outcomes of care [9-13, 48].

In this study, the achievement of the control and treatment targets were assessed by the realization of a control measurement and the achievement of the recommended HbA1c level. As the HbA1c should be measured regularly, it was assessed whether HbA1c was measured during the years 2011-2012 among the type 2 diabetes patients. Only the latest measurement was used. The clinical outcomes of care were categorized as good $[\mathrm{HbA} 1 \mathrm{c}<7 \%(<53 \mathrm{mmol} / \mathrm{mol})]$ and poor $[\mathrm{HbA} 1 \mathrm{c} \geq 7 \%$ ( $\geq 53 \mathrm{mmol} / \mathrm{mol})]$ HbA1c levels among those patients whose HbA1c was measured. Only patients, who had at least 3 months between their diabetes diagnosis and their last $\mathrm{HbA1c}$ measurement were included in the analyses to guarantee an appropriate period for treatment effect.

\section{Statistical analyses}

First, a Chi square test $\left(\chi^{2}\right)$ of independence was used to compare differences in the achievement of the control and treatment targets between different area classes. At very first, it was tested whether $\mathrm{HbA1c}$ was measured equally often in the seven area classes. Next, we tested the differences of the measurement frequencies of patients living in and outside a population center. A similar test of independence was performed to investigate whether $\mathrm{HbA1c}$ was under the recommended level of less than $7 \%$ in patients in the seven area classes and in patients living in or outside a population center.

Second, logistic regression analysis was used to test which variables affect the probability that HbA1c is measured and the probability that HbA1c is less than $7 \%$ (dependent variables). Both the patient's individual characteristics (patient's age, gender and road distance from a patient's home to the health care center) and the patient's neighborhood characteristics (the percentage of educated people, the percentage of the unemployed and the median income) were set as independent variables. The 7-class classifications of urban and rural areas were used as independent variables so that sparsely populated rural areas was the reference category. Additionally, the dichotomous variable of living in a population center was used as an independent variable.

\section{Results}

The average road distance from a patient's home to the health care center was $2.1 \mathrm{~km}$ in population centers and $14.9 \mathrm{~km}$ outside them. The longest distance was $92 \mathrm{~km}$. The majority (approx. $70 \%$ ) of patients were living within a $5-\mathrm{km}$ radius from the health care center. Table 2 presents the results of the dependence of the achievement of the control and treatments target by the seven area classes and Table 3 presents the results by the simple dichotomous variable of urban and rural.

The best control measurement rates were found in peri-urban areas, rural heartland areas and rural areas close to urban areas (Fig. 1). In all of these classes approximately $85 \%$ of the patients had gone through the HbA1c measurement. The weakest situation was in local centers in rural areas where HbA1c was measured in $79.9 \%$ of the patients. The best results for HbA1c level lower than $7.0 \%$, were found in outer and inner urban areas and peri-urban areas. The worse outcomes of care were found again in local centers in rural areas and especially in sparsely populated rural areas. The differences between the seven area classes related to the achieved treatment targets were statistically significant. However, there were no statistically significant differences in existence of the control measurement or achieving the recommended level of HbA1c when the dichotomous variable of urban and rural was under investigation (Table 3 ). The control measurement results $(83 \%)$ were the same for both urban and rural patients but urban patients achieved the 
Table 2 Realization of the control measurement and achieving the recommended level of $\mathrm{HbA1c}$ by 7-class area classification

\begin{tabular}{|c|c|c|c|c|}
\hline $\begin{array}{l}\text { 7-class classification } \\
\text { of areas }\end{array}$ & $\begin{array}{l}\text { Numbers of patients } \\
\text { and their areal percentage } \\
\text { distribution }\end{array}$ & $\begin{array}{l}\text { Proportions of } \mathrm{HbA} 1 \mathrm{c} \\
\text { measured patients } \mathrm{s}^{\mathrm{a}} \text { to the } \\
\text { diagnosed (\%) }\end{array}$ & $\begin{array}{l}\text { Proportions of } \mathrm{HbA} 1 \mathrm{c} \\
<7 \% \text { patients } \\
\text { measured to the } \\
\text { me) }\end{array}$ & $\begin{array}{l}\text { Patients' mean driving } \\
\text { distances and the } \\
\text { ranges }^{\mathrm{b}} \text { in } \mathrm{km}\end{array}$ \\
\hline Inner urban area & $849(8.8 \%)$ & 82.8 & 74.8 & $2.0(0-4.0)$ \\
\hline Outer urban area & $1433(14.9 \%)$ & 80.5 & 75.6 & $2.1(0-9.5)$ \\
\hline Peri-urban area & $644(6.7 \%)$ & 85.6 & 74.8 & $5.0(0.1-27.1)$ \\
\hline Local centers in rural areas & $1414(14.7 \%)$ & 79.9 & 69.2 & $1.8(0-5.7)$ \\
\hline Rural areas close to urban areas & $725(7.5 \%)$ & 84.6 & 71.8 & $7.8(0-27.9)$ \\
\hline Rural heartland areas & $2376(24.7 \%)$ & 84.9 & 73.1 & $6.0(0-36.0)$ \\
\hline Sparsely populated rural areas & 2165 (22.5\%) & 83.5 & 66.7 & $12.1(0-91.8)$ \\
\hline Total & $9606(100 \%)$ & & & $5.9(0-91.8)$ \\
\hline
\end{tabular}

${ }^{a} x^{2} p$ value $<0.05$

${ }^{\mathrm{b}}$ Minimum and maximum values in brackets

Table 3 Realization of the control measurement and achieving the recommended level of HbA1c by 2-class area classification

\begin{tabular}{llll}
\hline $\begin{array}{l}\text { 2-class classification } \\
\text { of areas }\end{array}$ & $\begin{array}{l}\text { Numbers of patients } \\
\text { and their areal percent- } \\
\text { age distribution }\end{array}$ & $\begin{array}{l}\text { Proportions of HbA1c } \\
\text { measured patients to the } \\
\text { diagnosed (\%) }\end{array}$ & $\begin{array}{l}\text { Proportions of HbA1c } \\
<7 \% \text { patients to the } \\
\text { measured (\%) }\end{array}$ \\
\hline $\begin{array}{l}\text { Population } \\
\text { center = urban }\end{array}$ & $6754(70.3 \%)$ & 83.0 & 72.0 \\
$\begin{array}{l}\text { Outside population the ranges } \mathbf{a}^{\mathbf{a}} \text { in km } \\
\text { center = rural }\end{array}$ & $2852(29.7 \%)$ & 83.0 & 70.7 \\
$\begin{array}{l}\text { Total } \\
\text { and }\end{array}$ & $9606(100 \%)$ & & $14.9(1-91.8)$ \\
\hline
\end{tabular}

a Minimum and maximum values in brackets

recommended level of HbA1c a little more often, but as mentioned, the result was not statistically significant.

Table 4 presents which variables affect the probability that HbA1c is measured and that HbA1c is less than $7 \%$ tested by the logistic regression models. The variables that remained statistically significant at the level of $\mathrm{p}$ value below 0.05 are included in the table. The probability of HbAlc measurements increased with ageing. The level of education in the neighborhood also increased the probability of attendance at HbA1c screenings. Compared with patients in inner urban areas, outer urban areas and local centers in rural areas, patients in sparsely populated rural areas had their $\mathrm{HbA1c}$ measured more often. Female gender and younger age increased the probability of achieving the recommended HbA1c level of $7 \%$. Surprisingly, the model suggests that when the road distance from a patient's home to the health care center increases it is more probable that HbA1c is less than $7 \%$. Additionally, when sparsely populated rural areas are compared with other area classes, all the other areas perform better in achieving the recommended level of HbA1c. The dichotomous variable of population centers did not remain in the model.
The findings from logistic regression models confirm the findings from Tables 2 and 3 that a more refined area classification reveals spatial differences in the achievement of the control and treatment targets. If the patient group is merely divided into the two categories of urban and rural, no differences are found in the achievement of the control or treatment targets. If the broader, more detailed classification of urban and rural is used, differences between specific area types are observed.

\section{Discussion}

The aim of the study was to find out whether the area classifications significantly influence the area-level results of achieving the targets of control and treatment among type 2 diabetes patients. The results have been statistically tested to understand the risk in the interpretation of results in the research area. As most phenomena are geographically contingent [49], we do not aim at making generalizations about the likely transferability of findings to other regions although statistically significant results indicate that similar differences are possible to exist elsewhere. 
Table 4 Effect of patient characteristics, area-level factors and area classes on achieved treatment targets

\begin{tabular}{|c|c|c|}
\hline Variable & Is HbA1c measured? ( $0=$ no, $1=$ yes) & HbA1c level ( $0=7 \%$ and over, $1=$ less $7 \%)$ \\
\hline Gender $(0=$ male, $1=$ female $)$ & & $1.22(1.10-1.35)$ \\
\hline Age & $1.02(1.02-1.03)$ & $0.99(0.99-1.00)$ \\
\hline Educated (\%) & $1.02(1.01-1.04)$ & \\
\hline \multicolumn{3}{|l|}{ Unemployed (\%) } \\
\hline \multicolumn{3}{|l|}{ Median income (thousands/€) } \\
\hline Distance $(\mathrm{km})$ & & $1.01(1.00-1.02)$ \\
\hline Inner urban area & $0.57(0.39-0.83)$ & $1.63(1.32-2.03)$ \\
\hline Outer urban area & $0.56(0.40-0.79)$ & $1.64(1.36-1.97)$ \\
\hline Peri-urban area & & $1.53(1.22-1.91)$ \\
\hline Local centers in rural areas & $0.67(0.56-0.81)$ & $1.23(1.02-1.46)$ \\
\hline Rural areas close to urban areas & & $1.33(1.08-1.65)$ \\
\hline Rural heartland areas & & $1.42(1.23-1.65)$ \\
\hline Sparsely populated rural areas & Reference category & Reference category \\
\hline \multicolumn{3}{|c|}{ Pop. center ( $0=$ outside, $1=$ inside) } \\
\hline$R^{2}$ & 0.022 & 0.014 \\
\hline
\end{tabular}

The logistic regression models revealing the effects of patient characteristics, neighborhood characteristics, area classes or the dichotomy of urban and rural on the HbA1c control measurement and the achievement of the recommended HbA1c level. The odds ratios (OR) with confidence intervals (Cl) of the variables that remained statistically significant $(p<0.05)$ in the models are presented in the table

Our first research task was to clarify whether differences in the achievement of the control and treatment targets among type 2 diabetes patients exist in different area classes. We applied 2-class and 7-class grid based classifications of urban and rural areas. When the simple dichotomy of urban and rural was used, no differences were found in the achievement targets assessed by the realization of the control measurement and the achievement of the recommended HbA1c level. The detailed classification with seven different area classes revealed statistically significant spatial differences in the achievement of control and treatment targets. These results strongly indicate that it is more informative to apply a more refined area classification than a simple urbanrural dichotomy, as has also been suggested earlier [16, 19, 20]. The comparison of achievement of control and treatment targets in diabetes care within a detailed area classification can help to identify areas at risk in a finer scale. Different results from 2-class and 7-class classifications of urban and rural areas indicate that the classification methods and classification principles chosen can easily affect the results and conclusions. Classifications can even be contradictory. For instance, several population centers in the 2-class classification of urban areas belong to rural heartland areas or sparsely populated rural areas in the 7-class classification (Fig. 1). The different choices of areal units (whether it is based on administrative borders, grids or something else) affect the results, which should be kept in mind especially when comparing studies and results between countries.
The analyses for the testing of the second hypothesis revealed that differences in the existence of control measurement between urban and rural areas were not due to the remote location of the rural patients as the road distance from a patient's home to the health care center was not a significant factor in explaining the control measurement rate. For the achievement of recommended HbA1c level, the model suggested that when the distance increases it is more probable that the recommended HbA1c level is achieved. This clearly states that the distance is not a barrier to good control or to achieve treatment targets.

Even though rural patients have to travel from longer distances to health care services than their urban counterparts, the distances are not that hindering in the care of type 2 diabetes in the study region. In Australia, for example, the distances can be much longer, producing a bigger barrier to the accessibility of health care [41]. In case of a need for control measurement the visits to the health care services can be planned beforehand and combined with other errands run in local centers. Moreover, the National Health Insurance scheme, which is part of the Finnish social security system, provides the reimbursement of health care related travel costs and accepts travel by taxi if a patient is unable to use a less expensive mode of transport for health reasons or if public transport is not available [50].

The analyses revealed some additional findings and issues. Firstly, regardless of the distance, inequalities in diabetes care exist, and these are partly due to a patient's 
individual characteristics such as gender and age. Also urban and rural neighborhoods seem to matter which reflect individual characteristics and status to a high degree. However, these individual and area-level variables explain only a small part of the variation. Clearly, local differences exist but it would be misleading to state that these differences are simply due to the urban or rural location. Smith et al. in their review [51] indicate that rurality per se does not necessarily lead to rural-urban disparities, but for example it may exacerbate the effects of socio-economic disadvantages. This can be observed for example when economic growth takes place predominantly in cities leading to selective migration of the healthier. Inequalities by area types in health care mainly stem from differences in their socio-economic and demographic characteristics $[16,19,21]$, originated from their socio-economic legacy and selective migration [52-54]. This can be seen to be the case in our study region as well. One of the limitations of this study was that we were not able to analyze socio-economic characteristics and the ways of life (values, norms, nutrition etc.) on an individual level as these particulars are not available in patient records.

Secondly, the service structure of the health care system and the processes of care are important factors to achieve efficient care results. Even though clinical guidelines are a national standard and largely implemented, the performance in health care is hardly ever homogenous. Performance gaps evolve when society develops. The study indicates that combining information from different databases is cost-effective in comparison with surveys and it can be useful in planning, resourcing and targeting primary health care services. In this study, we were neither able to assess service structures or different processes of care nor to get individual socioeconomic characteristics of the patients. These factors might explain one part of the differences found in the achievement of control and treatment targets in diabetes care. Also patient's motivation to his/hers own care can play an important role in achieving the treatment targets. If such data could be inserted into patient record databases, future research could examine these factors cost-efficiently.

\section{Conclusions}

In conclusion, individual and area-level differences exist in the achievement of control and treatment targets of care of chronic conditions such as type 2 diabetes even in an area with a relatively homogenous public primary health care system. Geographical accessibility seems not to be a deteriorating factor in the care of type 2 diabetes. The patient's gender and age, area-level education as a surrogate and the area class they belonged to were associated with achievement of control and treatment targets, and thus such information could be utilized much more in planning, resourcing and targeting the health care services. However, these factors explained only a small part of the variation. More information on the impact of processes and resources in health care and individual level characteristics are needed to obtain a comprehensive picture of factors predicting variation in the outcomes of care, but even so area-level information seems to be suggestive, at least for small-area health care planning.

\section{Authors' contributions}

Maija Toivakka performed the analyses and wrote the manuscript. TL and MT (Markku Tykkyläinen) contributed to the analyses and their statistical interpretation. TL, MT and TK edited the manuscript. All authors read and approved the final manuscript.

\section{Author details}

${ }^{1}$ Department of Geographical and Historical Studies, University of Eastern Finland, P.O. Box 111, 80101 Joensuu, Finland. ${ }^{2}$ Institute of Public Health and Clinical Nutrition, University of Eastern Finland, Kuopio, Finland. ${ }^{3}$ Hospital District of North Karelia, Joensuu, Finland. ${ }^{4}$ Department of Chronic Disease Prevention, National Institute for Health and Welfare (THL), Helsinki, Finland.

\section{Acknowledgements}

This work was partly funded by the Finnish Foundation for Cardiovascular Research, Juho Vainio Foundation and Funding from the Research Committee of the Kuopio University Hospital Catchment Area for the State Research Funding. The rest of the funding came from the home institutions of the authors.

\section{Compliance with ethical guidelines}

\section{Competing interests}

The authors declare that they have no competing interests.

Received: 9 September 2015 Accepted: 15 September 2015 Published online: 30 September 2015

\section{References}

1. Hu FB. Globalization of diabetes: the role of diet, lifestyle, and genes. Diabetes Care. 2011;34:1249-57.

2. Guariguata L, Whiting DR, Hambleton I, Beagley J, Linnenkamp U, Shaw JE. Global estimates of diabetes prevalence for 2013 and projections for 2035. Diabetes Res Clin Pract. 2014;103(2):137-49.

3. Hill JO, Galloway JM, Goley A, Marrero DG, Minners R, Montgomery B, Peterson GE, Ratner RE, Sanchez E, Aroda VR. Scientific statement: socioecological determinants of prediabetes and type 2 diabetes. Diabetes Care. 2013;36:2430-9.

4. Zoungas S, Chalmers J, Ninomiya T, Li Q, Cooper ME, Colagiuri S, Fulcher G, de Galan BE, Harrap S, Hamet P, Heller S, MacMahon S, Marre M, Poulter N, Travert F, Patel A, Neal B, Woodward M, ADVANCE Collaborative Group. Association of $\mathrm{HbA} 1 \mathrm{c}$ levels with vascular complications and death in patients with type 2 diabetes: evidence of glycaemic thresholds. Diabetologia. 2012;55:636-43.

5. Rossi MC, Lucisano G, Comaschi M, Coscelli C, Cucinotta D, Di Blasi P, Bader G, Pellegrini F, Valentini U, Vespasiani G, Nicolucci A, AMD-QUASAR Study Group. Quality of diabetes care predicts the development of cardiovascular events: results of the AMD-QUASAR study. Diabetes Care. 2011;34(2):347-52.

6. American Diabetes Association. Economic costs of diabetes in the U.S. in 2012. Diabetes Care. 2013;36(4):1033-46. 
7. Dall TM, Yang W, Halder P, Pang B, Massoudi M, Wintfeld N, Semilla AP, Franz J, Hogan PF. The economic burden of elevated blood glucose levels in 2012: diagnosed and undiagnosed diabetes, gestational diabetes mellitus, and prediabetes. Diabetes Care. 2014;37(12):3172-9.

8. Grintsova O, Maier W, Mielck A. Inequalities in health care among patients with type 2 diabetes by individual socio-economic status (SES) and regional deprivation: a systematic literature review. Int J Equity Health. 2014;13:43.

9. Reisig V, Reitmeir P, Doring A, Rathmann W, Mielck A, KORA Study Group. Social inequalities and outcomes in type 2 diabetes in the German region of Augsburg. A cross-sectional survey. Int J Public Health. 2007;52:158-65.

10. Sundquist K, Chaikiat Å, León VR, Johansson S, Sundquist J. Country of birth, socioeconomic factors, and risk factor control in patients with type 2 diabetes: a Swedish study from 25 primary health-care centres. Diabetes Metab Res. 2011;27:244-54.

11. Geraghty EM, Balsbaugh T, Nuovo J, Tandon S. Using Geographic Information Systems (GIS) to assess outcome disparities in patients with type 2 diabetes and hyperlipidemia. J Am Board Fam Med. 2010;23:88-96.

12. Laraia BA, Karter AJ, Warton EM, Schillinger D, Moffet HH, Adler N. Place matters: neighborhood deprivation and cardiometabolic risk factors in the Diabetes Study of Northern California (DISTANCE). Soc Sci Med. 2012;74:1082-90.

13. Sikiö $M$, Tykkyläinen $M$, Tirkkonen $H$, Kekäläinen $P$, Dunbar J, Laatikainen T. Type 2 diabetes care in North Karelia Finland: do area-level socio-economic factors affect processes and outcomes? Diabetes Res Clin Pract. 2014;106(3):496-503.

14. Syed ST, Gerber BS, Sharp LK. Traveling towards disease: transportation barriers to health care access. J Commun Health. 2013;38(5):976-93.

15. Bourke L, Humphreys JS, Wakerman J, Taylor J. Understanding rural and remote health: a framework for analysis in Australia. Health Place. 2012;18(3):496-503.

16. McLafferty S, Wang F, Luo L, Butler J. Rural-urban inequalities in late-stage breast cancer: spatial and social dimensions of risk and access. Environ Plann B Plann Des. 2011;38(4):724-40.

17. Hart LG, Larson EH, Lishner DM. Rural definitions for health policy and research. Am J Public Health. 2005;95(7):1149-55.

18. Lim A, Asher MI, Ellwood E, Ellwood P, Exeter DJ. How are 'urban' and 'rural' defined in publications regarding asthma and related diseases? Allergol Immunopathol (Madr). 2014;42(2):157-61.

19. Riva M, Curtis S, Gauvin L, Fagg J. Unravelling the extent of inequalities in health across urban and rural areas: evidence from a national sample in England. Soc Sci Med. 2009;68(4):654-63.

20. Terashima M, Rainham DG, Levy AR. A small-area analysis of inequalities in chronic disease prevalence across urban and non-urban communities in the Province of Nova Scotia, Canada, 2007-2011. BMJ Open. 2014;4(5):e004459.

21. Lourenco AE. The meaning of 'rural' in rural health: a review and case study from Brazil. Glob Public Health. 2012;7(1):1-13.

22. Smith ML, Dickerson JB, Wendel ML, Ahn S, Pulczinski JC, Drake KN, Ory MG. The utility of rural and underserved designations in geospatial assessments of distance traveled to healthcare services: implications for public health research and practice. J Environ Public Health. 2013;. doi:10.1155/2013/960157.

23. Bibby P, Brindley P. Urban and rural area definitions for policy purposes in England and Wales: methodology (v1.0). Office for National Statistics. 2013. https://www.gov.uk/government/uploads/system/uploads/attachment_data/file/239477/RUC11 methodologypaperaug_28_Aug.pdf. Accessed 25 May 2015.

24. Dijkstra L, Poelman H. European Commission. Regional and Urban policy. Cities in Europe-the new OECD-EC definition. 2012. http://ec.europa. eu/regional_policy/sources/docgener/focus/2012_01_city.pdf. Accessed 29 Apr 2015.

25. Helminen V, Nurmio K, Rehunen A, Ristimäki M, Oinonen K, Tiitu M, Kotavaara O, Antikainen H, Rusanen J. Urban-rural classification. Reports of the Finnish Environment Institute 25 (abstract in English). 2014. http:// hdl.handle.net/10138/135861. Accessed 25 May 2015.

26. Finnish Environment Institute. Urban-rural classification. 2014. http:// www.ymparisto.fi/en-US/Living_environment_and_planning/Community_structure/Information_about_the_community_structure/Urbanrural_classification. Accessed 30 Apr 2015.
27. Official Statistics of Finland. Concepts and definitions. Locality. http:// www.stat.fi/meta/kas/taajama_en.html. Accessed 25 May 2015.

28. Official Statistics of Finland. Statistical database. Population Structure. Degree of urbanisation by area 31.12.2012. 2013. http://pxweb2.stat.fi/ database/StatFin/vrm/vaerak/vaerak_en.asp. Accessed 25 May 2015.

29. Penchansky R, Thomas JW. The concept of access: definition and relationship to consumer satisfaction. Med Care. 1981;19(2):127-40.

30. Cromley EK, MCLafferty SL. GIS and public health. New York: Guilford Press; 2012.

31. Guagliardo MF. Spatial accessibility of primary care: concepts, methods and challenges. Int J Health Geogr. 2004;3(1):3.

32. Higgs $G$. The role of GIS for health utilization studies: literature review. Health Serv Outcomes Res Method. 2009;9:84-99.

33. Delamater PL, Messina JP, Shortridge AM, Grady SC. Measuring geographic access to health care: raster and network-based methods. Int J Health Geogr. 2012;11(1):15.

34. Luo W, Qi Y. An enhanced two-step floating catchment area (E2SFCA) method for measuring spatial accessibility to primary care physicians. Health Place. 2009;15(4):1100-7.

35. McGrail MR. Spatial accessibility of primary health care utilising the two step floating catchment area method: an assessment of recent improvements. Int J Health Geogr. 2012;11:50.

36. McGrail MR, Humphreys JS. Measuring spatial accessibility to primary health care services: utilising dynamic catchment sizes. Appl Geogr. 2014;54:182-8.

37. Wang F, Luo W. Assessing spatial and nonspatial factors for healthcare access: towards an integrated approach to defining health professional shortage areas. Health Place. 2005;11(2):131-46.

38. Arcury TA, Gesler WM, Preisser JS, Sherman J, Spencer J, Perin J. The effects of geography and spatial behavior on health care utilization among the residents of a rural region. Health Serv Res. 2005;40(1):135-55.

39. Haggerty JL, Roberge D, Levesque JF, Gauthier J, Loignon C. An exploration of rural-urban differences in healthcare-seeking trajectories: implications for measures of accessibility. Health Place. 2014;28:92-8.

40. Butalia S, Patel AB, Johnson JA, Ghali WA, Rabi DM. Association between diabetic ketoacidosis hospitalizations and driving distance to outpatient diabetes centres in adults with type 1 diabetes mellitus. Can J Diabetes. 2014;38:451-5.

41. Skinner T, Allen P, Peach E, Browne JL, Pouwer F, Speight J, Dunbar JA. Does the shortage of diabetes specialists in regional and rural Australia matter? Results from Diabetes MILES—Australia. Diabetes Res Clin Pract. 2013;100(2):222-9.

42. Strom JL, Lynch CP, Egede LE. Rural/urban variations in diabetes self-care and quality of care in a national sample of US adults with diabetes. Diabetes Educ. 2011;37(2):254-62.

43. Strauss K, MacLean C, Troy A, Littenberg B. Driving distance as a barrier to glycemic control in diabetes. J Gen Intern Med. 2006;21(4):378-80.

44. Zgibor JC, Gieraltowski LB, Talbott EO, Fabio A, Sharma RK, Hassan K. The association between driving distance and glycemic control in rural areas. J Diabetes Sci Technol. 2011;5(3):494-500.

45. Official Statistics of Finland. Suomi postinumeroalueittain -palvelu (in Finnish). 2014. http://tilastokeskus.fi/tup/posnro/index.html. Accessed 8 July 2014.

46. Current Care Guidelines. Working group set up by the Finnish Medical Society Duodecim and the Finnish Respiratory Society. Finnish Medical Society Duodecim, Helsinki. 2015. http://www.kaypahoito.fi/web/english/home. Accessed 25 May 2015.

47. Diabetes (online). Current care guidelines. Working group set up by the Finnish Medical Society Duodecim and the Finnish Respiratory Society. Finnish Medical Society Duodecim, Helsinki. 2013. http://www.kaypahoito.fi/web/kh/suositukset/naytaartikkeli/tunnus/hoi50056. Accessed 8 Nov 2013.

48. American Diabetes Association. Standards of medical care in diabetes-2014. Diabetes Care. 2014;37(Suppl 1):S14-80.

49. Tykkyläinen M. Turmoil in rural communities as an extreme event exemplified by the cases of Hungary and the Russian North. Geographische Zeitschrift. 2015;103(1):37-55.

50. Social Insurance Institution of Finland. Reimbursements of travel costs. 2014. http://www.kela.fi/web/en/reimbursements-of-travel-costs. Accessed 20 May 2015. 
51. Smith KB, Humphreys JS, Wilson MG. Addressing the health disadvantage of rural populations: how does epidemiological evidence inform rural health policies and research? Aust J Rural Health. 2008;16(2):56-66.

52. Roto J, Grunfelder J, Rispling L. State of the Nordic Region 2013. Nordregio report 2014, 1. ISSN 1403-2503.
53. Lehtonen O, Tykkyläinen M. Spatial divergence in living standards during an economic growth phase in the periphery: a case study of North Karelia. Fennia. 2011;189(2):47-62.

54. Heikkilä E, Pikkarainen M. Research note differential population development in the regions of Finland. Popul Space Place. 2010;16(4):323-34.

Submit your next manuscript to BioMed Central and take full advantage of:

- Convenient online submission

- Thorough peer review

- No space constraints or color figure charges

- Immediate publication on acceptance

- Inclusion in PubMed, CAS, Scopus and Google Scholar

- Research which is freely available for redistribution

Submit your manuscript at

www.biomedcentral.com/submit

( BioMed Central 